\title{
Using High Fluoride Concentration Products in Public Policy: A Rapid Review of Current Guidelines for High Fluoride Concentration Products
}

\author{
Gail V.A. Douglas Martin P. Ramsdale Karen Vinall-Collier Julia I. Csikar
}

University of Leeds School of Dentistry, Leeds, UK

\section{Key Words}

Dental guidelines · Fluoride varnish · High fluoride

concentration toothpaste

\begin{abstract}
Despite improvements in dental caries levels since the widespread introduction of fluoride toothpastes, it is still a disease which is considered to be a priority in many countries around the world. Individuals at higher risk of caries can be targeted with products with a high fluoride concentration to help reduce the amount and severity of the disease. This paper compares guidance from around the world on the use of products with a high fluoride concentration and gives examples of how guidance has been translated into activity in primary care dental practice. A rapid review of electronic databases was conducted to identify the volume and variation of guidance from national or professional bodies on the use of products with a high fluoride concentration. Fifteen guidelines published within the past 10 years and in English were identified and compared. The majority of these guidelines included recommendations for fluoride varnish use as well as for fluoride gels, while a smaller number offered guidance on high fluoride strength toothpaste and other vehicles. Whilst there was good consistency in recommendations for fluoride varnish in particular, there was sometimes
\end{abstract}

a lack of detail in other areas of recommendation for other vehicles with a high fluoride concentration. There are good examples within the UK, such as the Childsmile project and Delivering Better Oral Health, which highlight that the provision of evidence-based guidance can be influential in directing scarce resources towards oral health improvements. Policy can be influenced by evidence-based national recommendations and used to help encourage dental professionals and commissioners and third-party payers to adopt higher levels of practices aimed at oral health improvement.

(c) 2016 The Author(s)

Published by S. Karger AG, Basel

Despite improvements in dental caries levels since the widespread introduction of fluoride toothpastes, it is still a disease which is considered to be a priority in many countries around the world. For some areas dental caries is prevalent in a large proportion of the population, whilst in others the burden of disease is more concentrated within a smaller proportion with high levels of caries. Those at higher risk of developing caries can be targeted with products with a high fluoride concentration to help reduce the amount and severity of the disease.

There has been a great deal of research conducted into the efficacy of products with a high fluoride concentration, much of which has been translated into systematic reviews

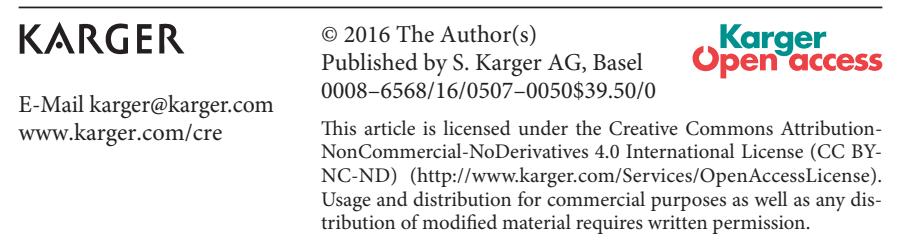

Prof. Gail V.A. Douglas

University of Leeds School of Dentistry

Worsley Building, Clarendon Way

Leeds LS2 9LU (UK)

E-Mail g.v.a.douglas@leeds.ac.uk 
Fig. 1. PRISMA flow diagram of rapid review [Moher et al., 2009].
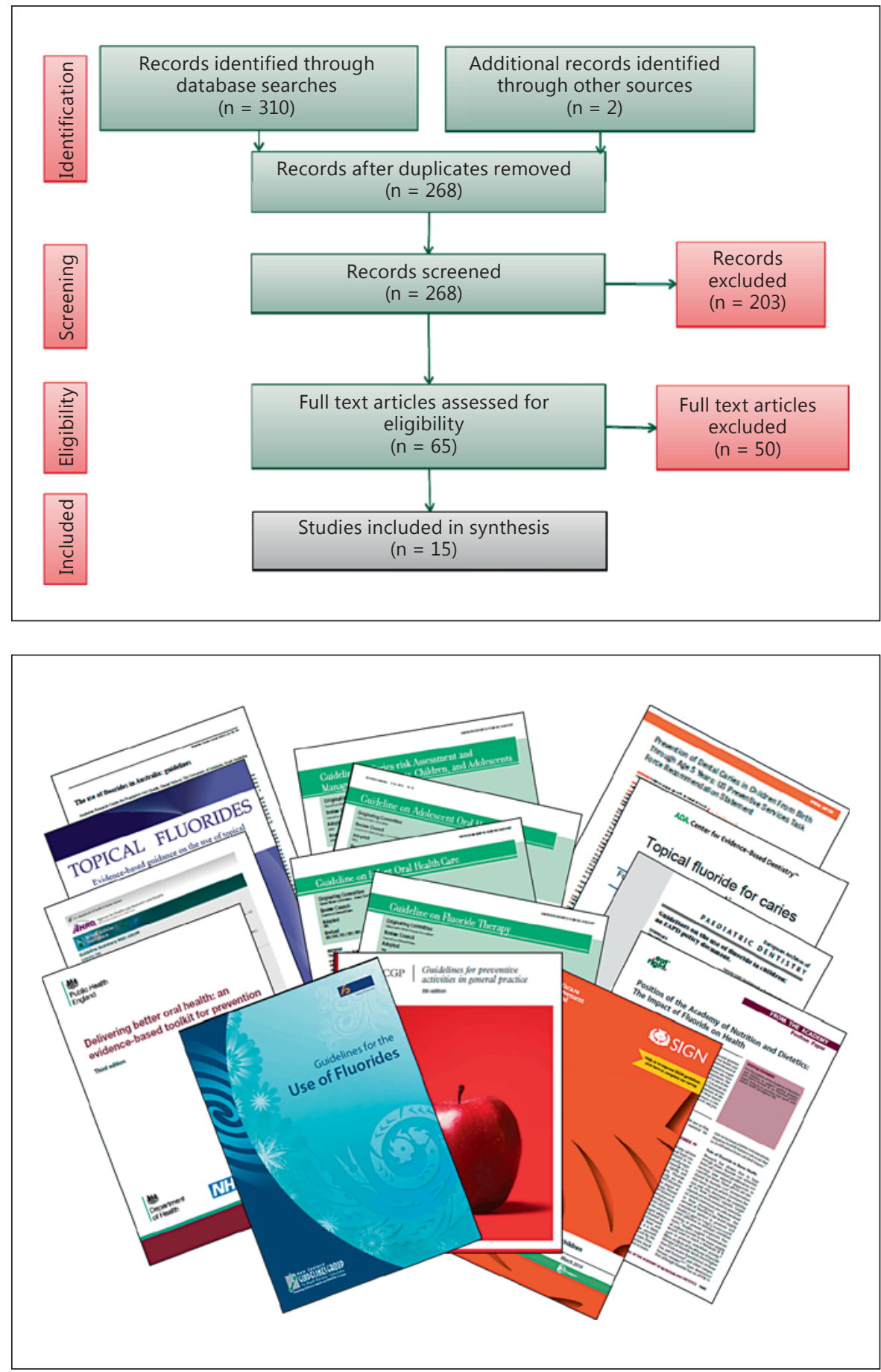

Fig. 2. Guidance documents identified.

to guide practitioners in the evidence base for prevention. In turn, such evidence has been summarised and presented as national guidance to assist in the dissemination of the evidence surrounding the prevention of caries. Often, it is the dental professional societies and associations who have

Public Policy Guidelines for High Fluoride Concentration Products taken on this role to encourage good practice. This paper aims to identify the volume and variation in national guidance from around the world on the use of products with a high fluoride concentration and to give a small number of examples of how guidance has been translated into activity 
Table 1. Results of database searching and assessment for inclusion

\begin{tabular}{|c|c|c|c|c|}
\hline Database & Retrieved & $\begin{array}{l}\text { After de- } \\
\text { duplication }\end{array}$ & $\begin{array}{l}\text { Full } \\
\text { text }\end{array}$ & Included \\
\hline MEDLINE & 152 & 148 & 31 & 4 \\
\hline EMBASE & 10 & 0 & 0 & 0 \\
\hline HMIC & 10 & 0 & 0 & 0 \\
\hline SCOPUS & 75 & 72 & 20 & 0 \\
\hline Web of science & 48 & 34 & 2 & 1 \\
\hline Cochrane & 0 & 0 & 0 & 0 \\
\hline TRIP & 3 & 2 & & 2 \\
\hline NHS evidence & 1 & 0 & 0 & 0 \\
\hline International Clinical Guideline Repository & 0 & 0 & 0 & 0 \\
\hline National Guidelines Clearing House & 7 & 7 & 7 & 6 \\
\hline Guidelines International Network & 0 & 0 & 0 & 0 \\
\hline CMA Infobase & 0 & 0 & 0 & 0 \\
\hline WHO Digital Library & 0 & 0 & 0 & 0 \\
\hline Scottish Intercollegiate Guidelines Network & 1 & 1 & 1 & 1 \\
\hline New Zealand Guidelines GP & 1 & 0 & 0 & 0 \\
\hline \multicolumn{5}{|c|}{ Australian National Health Medical Research Council and } \\
\hline eGuidelines & 2 & 2 & 2 & 0 \\
\hline Hand searching & 2 & 2 & 1 & 1 \\
\hline Total & 312 & 268 & 64 & 15 \\
\hline
\end{tabular}

in primary care dental practice. This review does not represent a systematic review of all such guidance but a retrieval of those which are readily available in English from a rapid review of electronic databases.

\section{Methods}

In order to identify national (and professional) guidelines on products with a high fluoride concentration, internationally, a search of the literature from the past 10 years was conducted to find guidelines and policy documents related to the use of products with a high fluoride concentration. Guidelines considering only lower concentrations of fluoride use such as water fluoridation, milk fluoridation and toothpaste below 1,500 ppm were excluded, as were those aimed at only specific population groups. The search strategy was specific, aimed at retrieving only English language guidance or policy documents restricted to dentistry which mentioned the use of products with a high fluoride concentration (e.g. fluoride varnish, mouth rinses, gel/paste/foam, toothpaste with a higher fluoride concentration).

Searches were conducted for guidelines reporting products with a high fluoride concentration use in the following databases:

- Peer-reviewed literature databases: MEDLINE, EMBASE, HMIC (Health Management Information Consortium) and Web of Science (using MeSH heading 'guidelines')

- Systematic review databases: Cochrane Library and DARE

- Guideline resource databases: TRIP, NHS Evidence, International Clinical Guideline Repository, National Guidelines Clearinghouse, Guidelines International Network, CMA Infobase,
WHO Digital library, NICE (UK), Scottish Intercollegiate Guidelines Network (Scotland), New Zealand Guidelines GP, Australian National Health Medical Research Council and eGuidelines All papers resulting from this search published within the last 10 years were considered for inclusion and only excluded on the basis of the following criteria:

1 Water fluoridation

2 Current and up-to-date guidelines only, previous versions excluded

3 Guidance older than 10 years

4 Guidance aimed only at specific populations (e.g. those with a condition such as molar incisor hypomineralisation)

5 Systemic fluoride products (e.g. salt, fluoridated milk)

6 'Normal' toothpastes (below 1,500 ppm)

7 Mouthwashes not containing fluoride (e.g. chlorhexidine if fluoride not mentioned)

After the initial screening of titles and abstracts, those guidelines which met, or appeared to meet, the inclusion criteria had their full text retrieved and were reviewed by two reviewers. Full papers that did not meet the inclusion criteria at this stage were excluded. References in the identified studies were checked and included where relevant and duplicates were discarded.

For papers meeting the inclusion criteria, data extraction was undertaken using a customised data extraction proforma. The data extracted included the following for comparison between guidelines: title of guidelines and country of origin, age group of target populations, products recommended, concentration recommended, whether application is professionally or self-administered and, finally, any other detail with regard to application (e.g. frequency of use). If a document gave only general recommendations regarding the use of a high-fluoride product it was not included any further. 
Table 2. Current guidelines specifying recommendations on products with a high fluoride concentration

\begin{tabular}{|c|c|c|c|c|}
\hline \multirow[t]{2}{*}{ Title } & \multirow{2}{*}{$\begin{array}{l}\text { Country/ } \\
\text { region }\end{array}$} & \multirow[t]{2}{*}{ Age } & \multicolumn{2}{|c|}{ Mode of fluoride application } \\
\hline & & & professional & self-applied \\
\hline Delivering Better Oral Health [Public Health England, 2014] & England & All & FV & Toothpaste \\
\hline $\begin{array}{l}\text { Dental interventions to prevent caries in children [Scottish Intercollegiate } \\
\text { Guidelines Network, 2014] }\end{array}$ & Scotland & Child & FV & Toothpaste \\
\hline $\begin{array}{l}\text { European Academy of Paediatric Dentistry (EAPD) Guidelines on the use } \\
\text { of fluoride in children: EAPD policy document [European Academy of } \\
\text { Paediatric Dentistry, 2009] }\end{array}$ & Europe & Child & FV, gel & \\
\hline $\begin{array}{l}\text { Evidence-based guidance on the use of topical fluorides for caries } \\
\text { prevention for children and adolescence in Ireland [Irish Oral Health } \\
\text { Service Guideline Initiative, 2008] }\end{array}$ & Ireland & Child & FV, gel & \\
\hline $\begin{array}{l}\text { Guidelines for preventive activities in general practice [Royal Australian } \\
\text { College of General Practitioners, 2012] }\end{array}$ & Australia & All & $\begin{array}{l}\text { Topical fluoride } \\
\text { pastes, gels }\end{array}$ & $\begin{array}{l}\text { Toothpaste, } \\
\text { gel, rinse }\end{array}$ \\
\hline Guidelines for the use of fluorides [New Zealand Guidelines Group, 2009] & New Zealand & All & FV, gel, foam & Rinse \\
\hline $\begin{array}{l}\text { Guideline on Adolescent Oral Health Care [American Academy of } \\
\text { Pediatric Dentistry, 2010] }\end{array}$ & USA & Child & Gel, paste & $\begin{array}{l}\text { Gel, paste, } \\
\text { rinse }\end{array}$ \\
\hline $\begin{array}{l}\text { Guideline on Caries Risk Assessment and Management for Infants, } \\
\text { Children, and Adolescents [American Academy of Pediatric Dentistry, } \\
\text { 2014a] }\end{array}$ & USA & Child & Topical fluoride & \\
\hline $\begin{array}{l}\text { Guideline on Fluoride Therapy [American Academy of Pediatric Dentistry, } \\
\text { 2014b] }\end{array}$ & USA & Child & FV, gel & \\
\hline $\begin{array}{l}\text { Guideline on Infant Oral Care [American Academy of Pediatric Dentistry, } \\
\text { 2014c] }\end{array}$ & & & & \\
\hline $\begin{array}{l}\text { HealthPartners Dental Group and Clinics caries guideline [HealthPartners } \\
\text { Dental Group, 2013] }\end{array}$ & USA & All & FV & Gel, paste \\
\hline $\begin{array}{l}\text { Position of the Academy of Nutrition and Dietetics: the impact of fluoride } \\
\text { on health [Academy of Nutrition and Dietetics, 2012] }\end{array}$ & USA & All & FV, gel & \\
\hline $\begin{array}{l}\text { Prevention of dental caries in children from birth through age } 5 \text { years: US } \\
\text { Preventive Services Task Force recommendation statement [Moyer, 2014] }\end{array}$ & USA & Child & FV & \\
\hline $\begin{array}{l}\text { The use of fluorides in Australia: guidelines [Australian Research Centre } \\
\text { for Population Oral Health, 2006] }\end{array}$ & Australia & All & FV, gel, foam & Rinse \\
\hline Topical fluoride for caries prevention [Weyant et al., 2013] & USA & All & FV, gel & $\begin{array}{l}\text { Fluoride } \\
\text { paste/gel, } \\
\text { rinse }\end{array}$ \\
\hline
\end{tabular}

FV = Fluoride varnish.

\section{Results}

The results of the rapid review process to identify national/professional guidelines are shown in the PRISMA flow diagram in figure 1 . All searches found 312 papers, of which 44 were duplicates. Abstracts of 268 publications were screened, of which 204 were excluded as they did not meet the inclusion/exclusion criteria. Sixty-four full-text articles were retrieved and assessed against the inclusion/ exclusion criteria and 15 of these were included in the final qualitative synthesis (table 1; fig. 2).

A variety of current guidance documents which include specific guidance on the use of products with a high fluoride concentration was readily identifiable. Table 2 shows which products with high fluoride concentration were considered within each of the 15 current national/ professional guidelines identified. All gave guidance on both professionally applied products and around half included guidance on self-administered products with a high fluoride concentration $(n=8)$, though the level of detail in the recommendations varied, as well as there being great variation in how the fluoride content was presented.

Out of the national guidelines reviewed, the most commonly recommended professionally applied fluoride product with a high concentration was fluoride varnish, 
Table 3. Summary of guidance on fluoride varnish

\begin{tabular}{|c|c|c|c|}
\hline Guideline & Age & Fluoride concentration & Other process (e.g. 2/day) \\
\hline American Academy of Pediatric & Primary teeth & $\mathrm{NaF} 22,500 \mathrm{ppm}$ & 2/year \\
\hline Dentistry [2014] & Permanent teeth & $\mathrm{NaF} 22,500 \mathrm{ppm}$ & $2-3 /$ year \\
\hline $\begin{array}{l}\text { American Academy of Pediatric } \\
\text { Dentistry [2014c] }\end{array}$ & By age 12 months & Not specified & Initial visit if indicated \\
\hline \multirow{3}{*}{$\begin{array}{l}\text { Academy of Nutrition and } \\
\text { Dietetics [2012] }\end{array}$} & $<6$ years & Not specified & 2/year (moderate or high caries risk) \\
\hline & $6-18$ years & Not specified & $\begin{array}{l}\text { 2/year (moderate caries risk) } \\
2-4 / \text { year (high caries risk) }\end{array}$ \\
\hline & $18+$ years & Not specified & 2 or $2-4 /$ year (moderate and high caries risk) \\
\hline $\begin{array}{l}\text { Australian Research Centre for } \\
\text { Population Oral Health [2006] }\end{array}$ & $0-10$ years & $22.6 \mathrm{mg} / \mathrm{ml}$ fluoride ion & $\begin{array}{l}\text { Where other forms of professionally applied } \\
\text { fluoride are contra-indicated } \\
\text { Where other professionally applied fluoride } \\
\text { vehicles may be unavailable or impractical }\end{array}$ \\
\hline Weyant et al. [2013] & All & $2.26 \%$ & $2-4 /$ year \\
\hline
\end{tabular}

Table 4. Summary of guidance on high fluoride concentration toothpaste

\begin{tabular}{|c|c|c|c|}
\hline Guideline & Age & Concentration & Other process (e.g. 2/day) \\
\hline \multirow[t]{2}{*}{$\begin{array}{l}\text { Delivering Better Oral Health } \\
\text { [Public Health England, 2014] }\end{array}$} & $\begin{array}{l}10+\text { years with active } \\
\text { caries }\end{array}$ & $2,800 \mathrm{ppm}$ & $\begin{array}{l}\text { 2/day (brush last thing at night } \\
\text { and at least on } 1 \text { other } \\
\text { occasion) }\end{array}$ \\
\hline & $\begin{array}{l}16+\text { years with active } \\
\text { disease }\end{array}$ & $\begin{array}{l}2,800 \text { or } \\
5,000 \mathrm{ppm}\end{array}$ & $\begin{array}{l}\text { 2/day (brush last thing at night } \\
\text { and at least on } 1 \text { other } \\
\text { occasion) }\end{array}$ \\
\hline $\begin{array}{l}\text { Dental interventions to prevent caries in children } \\
\text { [Scottish Intercollegiate Guidelines Network, 2014] }\end{array}$ & $10-16$ years at risk & $2,800 \mathrm{ppm}$ & At least twice daily \\
\hline $\begin{array}{l}\text { Guidelines for preventive activities in general practice } \\
\text { [Royal Australian College of General Practitioners, 2012] }\end{array}$ & All & Not specified & $\begin{array}{l}\text { Encourage home use of high } \\
\text { fluoride toothpastes }\end{array}$ \\
\hline
\end{tabular}

in which 12 out of the 15 guidelines considered this modality (table 3). Most guidelines specified a concentration of fluoride and were all consistent in their recommendation of the equivalent of approximately $22,600 \mathrm{ppm}$. Although there were variations in the recommended frequency of application, there was agreement that fluoride varnish should be applied at least twice per year.

Three guidelines recommended the use of higher fluoride concentration toothpaste, though 1 did not specify the concentration and frequency (where their guidance overlapped it was entirely consistent; table 4).
With regard to other vehicles with a high fluoride concentration, the guidelines identified in this review found that the majority included recommendations on gels and pastes ( $\mathrm{n}=11$; table 5$)$ for both professional and self-application and on high fluoride concentration mouth rinses $(n=5$; table 6$)$, though the definition of 'high fluoride' was not always clear. The guidance on the use of fluoride gel, pastes, foams and rinses was the most variable in terms of the level of detail on which product to use as well as in terms of the appropriate age groups and frequency of use. Most of the guidance in this product range fo- 
Table 5. Summary of guidance on high fluoride concentration gels, pastes and foams

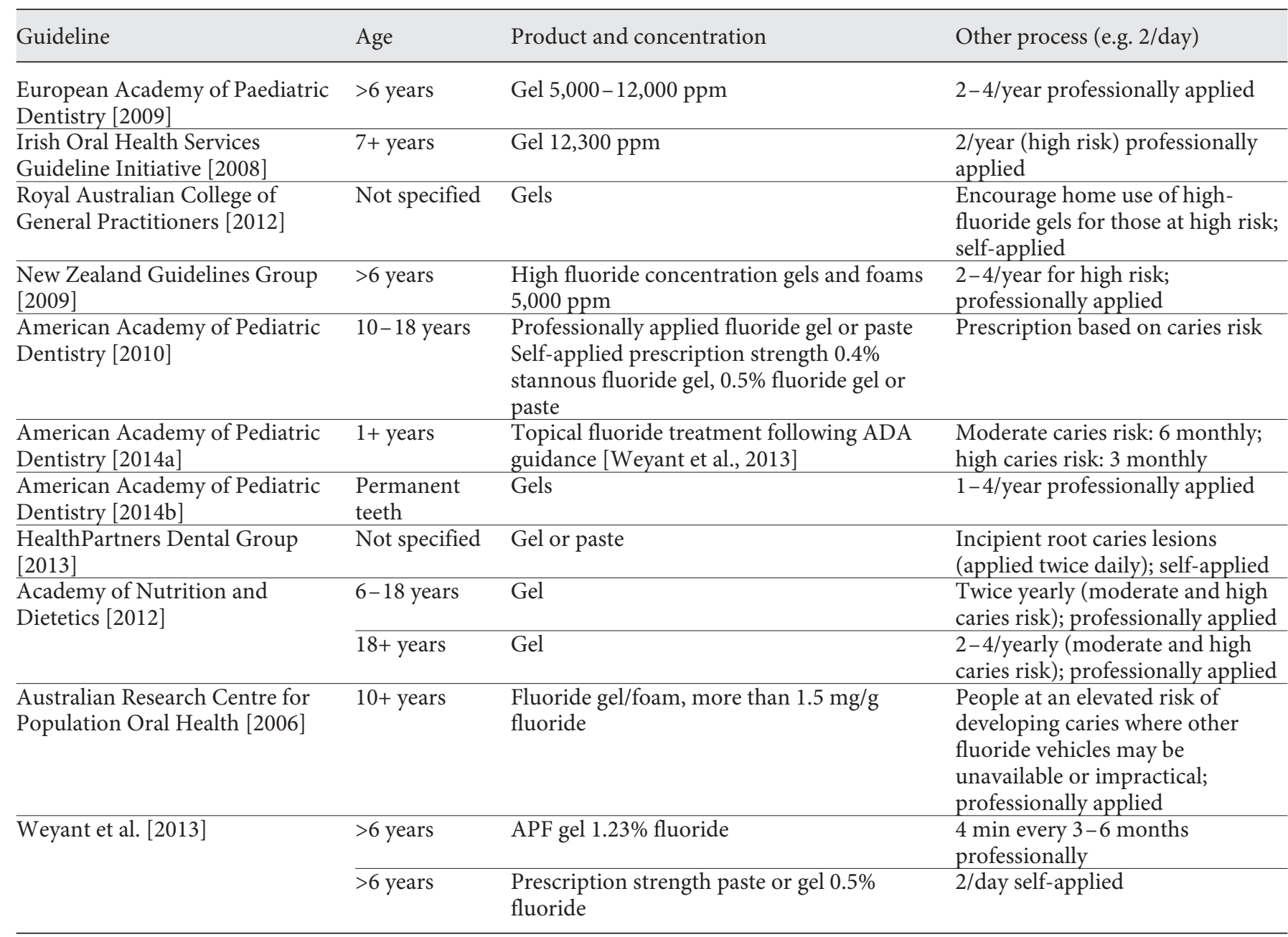

Table 6. Summary of guidance on high fluoride concentration mouth rinses

\begin{tabular}{|c|c|c|c|}
\hline Guideline & Age & Product and concentration & Other process (e.g. 2/day) \\
\hline $\begin{array}{l}\text { Guidelines for preventive activities in general } \\
\text { practice [Royal Australian College of General } \\
\text { Practitioners, 2012] }\end{array}$ & $\begin{array}{l}\text { Not } \\
\text { specified }\end{array}$ & Fluoride mouth rinse & $\begin{array}{l}\text { Encourage home use of high fluoride con- } \\
\text { centration mouth rinses for those at high } \\
\text { risk }\end{array}$ \\
\hline $\begin{array}{l}\text { Guidelines for the use of fluorides [New Zea- } \\
\text { land Guidelines Group, 2009] }\end{array}$ & $>6$ years & Prescription strength & $\begin{array}{l}\text { For those at high risk of developing dental } \\
\text { caries, fluoride mouth rinse should be used } \\
\text { as part of a preventive oral health plan }\end{array}$ \\
\hline $\begin{array}{l}\text { Guideline on Adolescent Oral Health Care } \\
\text { [American Academy of Pediatric Dentistry, } \\
\text { 2010] }\end{array}$ & $\begin{array}{l}10-18 \\
\text { years }\end{array}$ & Mouth rinse $0.2 \% \mathrm{NaF}$ & $\begin{array}{l}\text { If indicated by an individual's caries pat- } \\
\text { tern or caries risk status }\end{array}$ \\
\hline
\end{tabular}

$\begin{array}{ll}\text { The use of fluorides in Australia: guidelines } & >6 \text { years }\end{array} \begin{aligned} & \text { Fluoride ion concentration } \\ & \text { of } 900 \mathrm{mg} / \mathrm{l}\end{aligned}$

Oral Health, 2006]

Topical fluoride for caries prevention [Weyant $>6$ years Mouth rinse $0.09 \%$ fluoride At least weekly and daily for root caries et al., 2013]

Public Policy Guidelines for High Fluoride Concentration Products 
cussed on high fluoride concentration gels but a comparison between recommendations is limited by a paucity of detail and variation in product concentration and frequency.

\section{Discussion}

As illustrated in this rapid review of English language publications within the past 10 years, there are a number of national guidance documents available on the use of products with a high fluoride concentration which are available for dental professionals. Although the recommendations vary between publications, there is good consistency on the use of fluoride varnish in particular. Variation between guidelines in this review in relation to other products with a high fluoride concentration may be a feature of the differences between countries in the products which are available and most widely used.

In general, whilst guidance on the use of some high fluoride concentration vehicles such as fluoride varnish was detailed and specific in most documents, that relating to other high fluoride concentration products was often generalised. This was to the point of being unhelpfully lacking in detail to allow practitioners, or indeed commissioners or third-party payers, to nudge oral health care towards the most effective means of preventing caries.

The value of clear guidance can best be demonstrated through some examples of how evidence-based recommendations can be implemented into best practice for the benefit of oral health improvement in dental patients and the population in general. Amongst the 15 guidelines considered in this review, 2 were published in the UK: The Scottish Intercollegiate Guidelines Network (SIGN) guideline aimed at children's oral health in Scotland [Scottish Intercollegiate Guidelines Network, 2014] and Delivering Better Oral Health [Public Health England, 2014] released in England and aimed at improving oral health in both children and adults.

The example from Scotland illustrates how the provision of evidence-based guidance can be very compelling in influencing policy and investment in oral health in combination with epidemiological evidence showing the need for oral health improvement.

The Scottish Executive has invested millions of pounds into improving oral health through a number of programmes aimed at different vulnerable populations [Scottish Executive, 2005]. One of these is the Childsmile programme [Macpherson et al., 2010] where the emphasis is on improving oral health of children where the invest-



Fig. 3. Trends in the percentage of Scottish 5-year-olds without obvious dentinal decay from 2004 to 2014 (from Scottish National Dental Inspection Programme data 2004-2014).

ment has potential for lifelong benefits. Two guidelines from the SIGN on the subject of caries prevention in children (guidelines 47 and 83) were pivotal in helping to decide which interventions would be the focus for investment nationally [Scottish Intercollegiate Guidelines Network, 2000, 2005]. The interventions chosen were based upon fluoride toothpaste distribution and use, fissure sealants and fluoride varnish. The latter is utilised within both Childsmile Practice and Childsmile Nursery, respectively encouraging at least a twice-yearly application of fluoride varnish in high caries risk infants under 2 years born in deprived communities by dental professionals in general dental practice and within school-based fluoride varnish schemes for children aged 3 years and over attending priority nurseries and schools.

In the past 8 years, Scottish National Dental Inspection Programme data suggest that the combination of oral health promotion initiatives within Childsmile is having a significant impact on the oral health of Scotland's 5-year-olds [Scottish Dental Epidemiology Co-Ordinating Committee, 2014] (fig. 3). There is evidence, however, from activity data in relation to fluoride varnish applications from Childsmile's national monitoring data to show that the rates of application are not as high as might be desired. While the majority of children in 2010/2011 received one application of fluoride varnish, only $8 \%$ received a second application in line with evidence-based guidance [Central Evaluation and Research Team, 2012]. In April 2010, the Health Improvement, Efficiency, Access and Treatment (HEAT) target (H9) for child oral 
health was developed to focus on reaching the most disadvantaged children. This requires at least $60 \%$ of 3 - and 4 -year-old children in each Scottish Index of Multiple Deprivation (SIMD) quintile to receive at least two applications of fluoride varnish per year by 2014. Only two of the fourteen Health Boards in Scotland met this target, but overall the proportion of young children having at least two applications of fluoride varnish each year is increasing [Information Services Division, 2015].

In England the levels of dental caries in children generally have been lower than in their counterparts in Scotland. However, amongst 5-year-olds in particular there has been concern that improvements in oral health have been limited in the past decade and the prevention of caries in children is one of the high priorities for NHS dental commissioners.

In 2007 the first edition of Delivering Better Oral Health - An Evidence-Based Toolkit for Prevention was published by the Department of Health in partnership with the British Association for the Study of Community Dentistry [Department of Health, 2007]. Now in its third edition released in 2014 [Public Health England, 2014], the primary audience of the guidelines is health and social care professionals. There have been numerous initiatives undertaken around the country to implement the guidance, such as schemes to train dental nurses in the application of fluoride varnish in order to allow them to also provide such treatment under the authorisation of a group directive (permission given to allow appropriately trained individuals to be delegated to follow a specific protocol to provide a treatment that they would not ordinarily have been allowed to do). For example, free training for dental nurses in primary care has been provided with a view to using these valuable personnel to increase fluoride varnish use. The influence of evidence-based guidelines should not be underestimated. For example, Delivering Better Oral Health - An Evidence-Based Toolkit for Prevention in 2007 led to a range of positive changes that have increased the likelihood of people in England benefiting from improved oral health. The guidance states the minimum concentrations of fluoride in toothpaste to control caries and prompted several manufacturers to reformulate their children's toothpaste to a more effective level for caries control. Coupled with clear advice about twice-daily brushing, this is likely to have reduced caries activity among our very young children. Guidance regarding the important role of fluoride varnish as part of clinical activity to control caries has led to a large increase in the number of primary care teams applying this routinely and regularly to their child patients

Public Policy Guidelines for High Fluoride Concentration Products

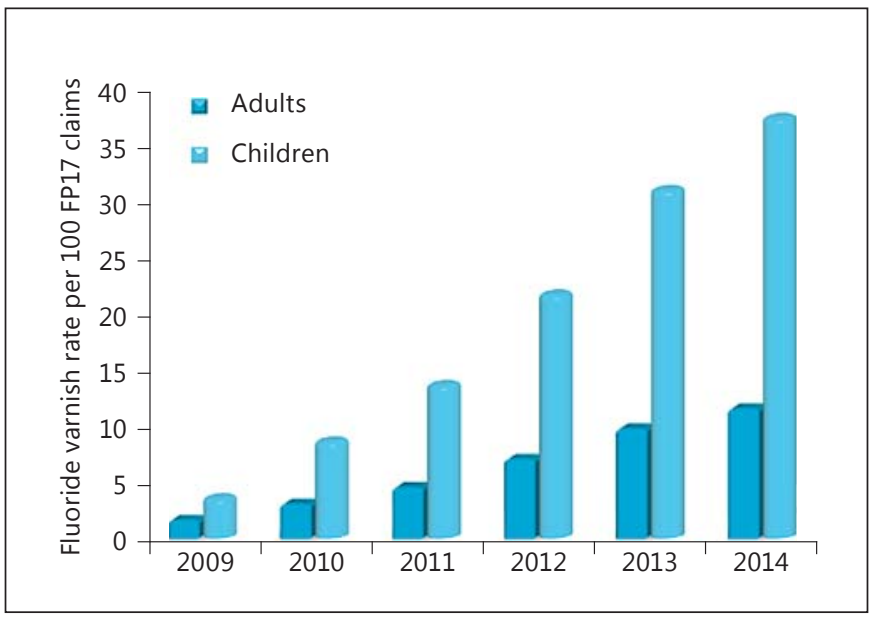

Fig. 4. Rates of claims for fluoride varnish in adults and children from 2009 to 2014 in Yorkshire and the Humber (from NHS Business Services Authority, FP17 claims for NHS dental care 20092014).

and to adults at higher risk. The simple item of advice that patients should spit out after brushing instead of rinsing away the fluoride in their toothpaste has been widely broadcast and should lead to lower caries levels among children, adolescents and adults.

In England, it is the role of NHS Dental Services and Information Services (NHSDIS) within the NHS Business Services Authority to process payment requests (form FP17) for NHS treatment and to make appropriate payments to dentists. Activity data from these payment claims can be used to examine the impact of national guidance. Figure 4 illustrates the trends in the numbers and proportion of payment claims from one region of England (Yorkshire and Humber) which include fluoride varnish since the release of the second edition of Delivering Better Oral Health in 2009 [Department of Health, 2009]. A clear year-on-year increase has been seen across the region and this is mirrored across England.

It is also the role of NHSDIS to monitor this payment data to quality assure and check the probity of NHS treatments and to take any necessary steps to rectify issues identified. In 2013, the NHSDIS reviewed the provision of topical fluoride treatment to children as part of their monitoring role. They discovered that despite an overall increase in fluoride varnish activity a number of general dental practices still had patterns of provision of fluoride varnish which were relatively low in comparison to the levels recommended by Delivering Better Oral Health (twice-yearly applications of fluoride varnish for all chil- 
Fig. 5. Reasons given for apparent low fluoride varnish application rates in England [NHS Business Services Agency Information Services, 2015].

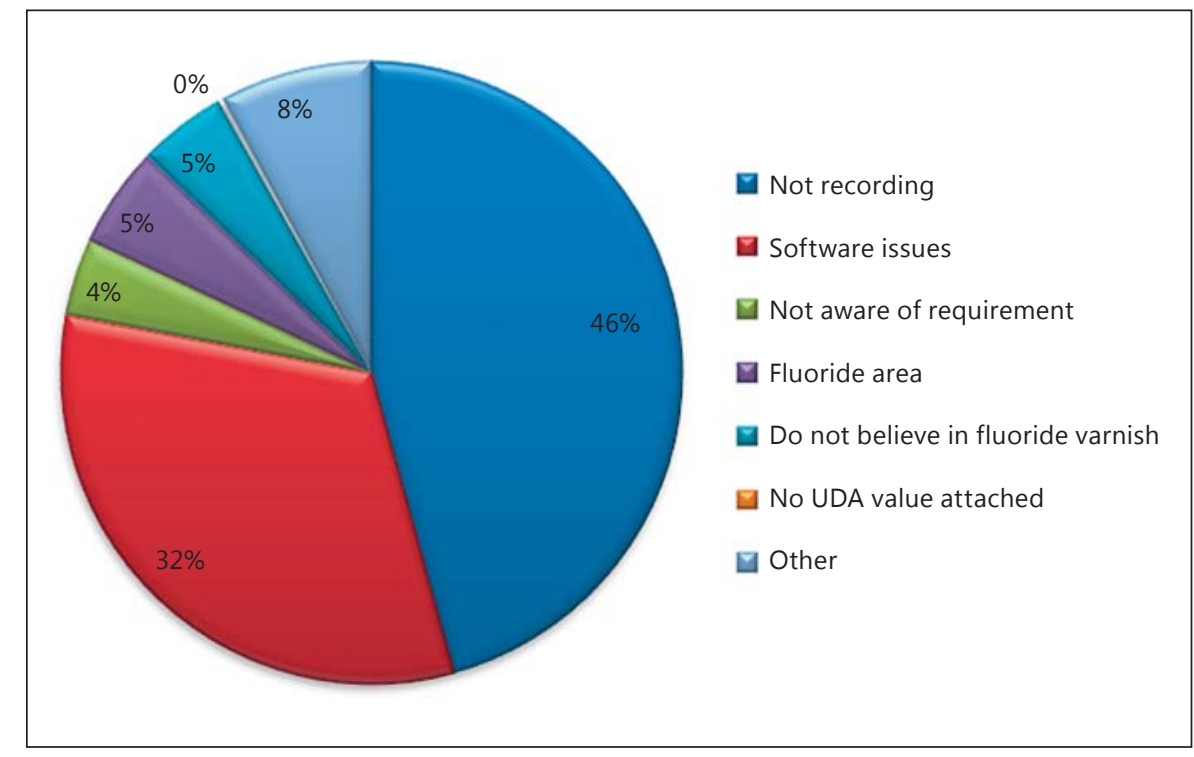

Table 7. Performance of practices with low fluoride varnish rate contracts before and after NHSDIS contact letter (open contracts only)

\begin{tabular}{|c|c|c|c|c|c|}
\hline Initial response category & Contracts & $\begin{array}{l}\text { FV rate } \\
\text { before }\end{array}$ & $\begin{array}{l}\text { FV rate } \\
\text { after }\end{array}$ & $\begin{array}{l}\text { Contracts with zero } \\
\text { rate before }\end{array}$ & $\begin{array}{l}\text { Contracts with } \\
\text { zero rate after }\end{array}$ \\
\hline Not recording & 324 & 0.1 & 12.8 & 288 & 69 \\
\hline Other & 44 & 0.1 & 4.3 & 42 & 14 \\
\hline Fluoride area & 37 & 0.1 & 4.1 & 31 & 14 \\
\hline Do not believe in FV & 36 & 0.2 & 8.4 & 31 & 15 \\
\hline No UDA value attached & 2 & 0 & 2.2 & 2 & 1 \\
\hline No response & 457 & 0.1 & 10.1 & 399 & 165 \\
\hline Total & 1,125 & 0.12 & 11.2 & 987 & 304 \\
\hline
\end{tabular}

Number of contracts in the no response category is higher than the overall non-response rate as it was not possible to match online responses to contract numbers [NHS Business Services Agency Information Services, 2015]. FV = Fluoride varnish.

dren and young adults and 3-4 times annually for children who are at high risk of developing caries) and also to the average level for similar practices in their locality.

As the payment claims from such practices suggested that they were not following best practice in relation to fluoride varnish application, the NHSDIS initiated a campaign ('The Fluoride Challenge') to first of all understand why the apparent rates of application were lower than expected and secondly to address the issue. A letter was sent to each NHS contract holder informing them that they appeared not to be providing the expected level of fluoride treatments. To illustrate this, a comparison was made with the national rate, their locality rate and other practices in their area (nearest 5 contracts). They were asked to complete a form to explain why fluoride treatment had not been provided more widely at their practice. Letters were sent to 1,161 practices and $76 \%$ responded $(n=885)$. The most common reasons given, accounting for $79 \%$ of all responses, were that either the treatment was not being recorded on the FP17 form or that there were software issues which resulted in the treatment not being recorded (fig. 5).

As a result of the challenge to dental practices whose rates of claims for fluoride varnish were low, there has 
been an increase in the reported activity in these practices, with fluoride varnish treatment claims increasing dramatically from 0.12 per $100 \mathrm{FP} 17$ forms prior to the NHSDIS challenge letters (from October to December 2012) to 11.2 after (from January to March 2013; table 7), although much of this may have been in relation to improvements in recording the activity data at the dental practices.

Further to the work of the NHSDIS, since March 2014 fluoride varnish has been included as an indicator within the new dental assurance framework in NHS England [Primary Care Commissioning, 2014]. The dental assurance framework outlines policy and high-level procedures to allow Area Teams to be able to assure themselves of the quality of primary care of dental services being delivered in their area. The inclusion of fluoride varnish rates as one of the indicators for quality of care is an example of how policy can be used to influence the uptake of evidence-based guidance.

These two examples from Scotland and England illustrate how influential national guidance can be in increasing the uptake of evidence-based practices and improving oral health.

\section{Conclusions}

This rapid review found national guidance on the use of high fluoride products published in a number of countries in the last 10 years, with the majority focussing on fluoride varnish use as well as gels. Whilst there was good consistency in recommendations for fluoride varnish in particular, there was sometimes a lack of detail in other areas of recommendation for other high-fluoride vehicles.

The provision of evidence-based guidance can be influential in directing scarce resources towards oral health improvements, as shown in the examples used for illustration in this paper. Policy can be influenced by evi- dence-based national recommendations and used to help encourage dental professionals and commissioners and third-party payers to adopt higher levels of practices aimed at oral health improvement. Whilst guidelines are recommendations, standards are mandatory (such as those implemented by the General Dental Council, GDC). The consequences of failure to follow mandatory GDC standards would be possible erasure from the GDC register, while failure to perform the guidelines such as those in Delivering Better Oral Health would not, unless it was possible to demonstrate significant and evidence-based detriment to patient care. The implementation of standards would assist with implementation. However, unless these were clearly described standards of the GDC (in the case of the UK), this is unlikely to occur.

\section{Acknowledgement}

The authors sincerely thank the NHS Business Services Agency Information Services for permission to use information from their report titled 'The Fluoride Challenge' and for providing fluoride activity data for Yorkshire and the Humber.

\section{Author Contributions}

G.V.A. Douglas, the primary author, was involved in the design of the rapid review, synthesis and the interpretation of guidelines, and was a presenter at the Fluoride Symposium. M.P. Ramsdale, co-author, was involved in literature searching and synthesis. K. Vinall-Collier, co-author, was involved in the design of the rapid review, literature search terms and synthesis of grey literature. J.I. Csikar, co-author, was involved in the design of the rapid review, literature searching, appraisal and synthesis, and sourced data for policy examples of the implementation of the guidelines.

\section{Disclosure Statement}

All authors declare that there are no conflicts of interest in relation to the subject matter of this paper.

\section{References}

Public Policy Guidelines for High

Fluoride Concentration Products
Academy of Nutrition and Dietetics: Position of the Academy of Nutrition and Dietetics: the impact of fluoride on health. 2012. http:// www.andeal.org/vault/2440/web/The_Impact_of_Fluoride_9-12.pdf (accessed February 6,2015$)$.

American Academy of Pediatric Dentistry: Guideline on Adolescent Oral Health Care. 2010. http://www.aapd.org/media/Policies_ Guidelines/G_Adoleshealth.pdf (accessed February 6, 2015).
American Academy of Pediatric Dentistry: Guideline on Caries Risk Assessment and Management for Infants, Children, and Adolescents. 2014a. http://www.aapd.org/media/ Policies_Guidelines/G_CariesRiskAssessment.pdf (accessed February 6, 2015).

American Academy of Pediatric Dentistry: Guideline on Fluoride Therapy. 2014b. http:// www.a a pd.org/media/ Policies Guidelines/G_fluoridetherapy.pdf (accessed February 6, 2015). 
American Academy of Pediatric Dentistry: Guideline on Infant Oral Health Care. 2014c. http://www.aapd.org/media/Policies_ Guidelines/G_infantOralHealthCare.pdf (accessed February 6, 2015).

Australian Research Centre for Population Oral Health: The use of fluorides in Australia: guidelines. Aust Dent J 2006;51:195-199.

Central Evaluation and Research Team: Childsmile National Headline Data. Glasgow, University of Glasgow, 2012.

Department of Health: Delivering Better Oral Health - An Evidence-Based Toolkit for Prevention, ed 1.2007. http://webarchive.nationalarchives.gov.uk/20130107105354/http:// www.dh.gov.uk/prod_consum_dh/groups/ dh_digitalassets/@dh/@en/documents/digitalasset/dh_078759.pdf (accessed February 6, 2015).

Department of Health: Delivering Better Oral Health - An Evidence-Based Toolkit for Prevention, ed 2. 2009. http://webarchive.nationalarchives.gov.uk/20100810041346/http:// dh.gov.uk/prod_consum_dh/groups/dh_ digitalassets/documents/digitalasset/ dh_102982.pdf (accessed February 6, 2015).

European Academy of Paediatric Dentistry: Guidelines on the use of fluoride in children an EAPD policy document. Eur Arch Paediatr Dent 2009;10:129-135.

HealthPartners Dental Group: HealthPartners Dental Group and Clinics caries guideline. Minneapolis, HealthPartners Dental Group 2013. http://www.guideline.gov/content. aspx?id=47755 (accessed February 6, 2015).

Information Services Division: Dental Statistics HEAT Target H9: Fluoride Varnishing for 3and 4-Year-Olds. 2015. https://isdscotland. scot.nhs.uk/Health-Topics/Dental-Care/ Publications/2015-01-27/2015-01-27-FluorideVarnish-Report.pdf?88344973326 (accessed February 6, 2015).
Irish Oral Health Services Guideline Initiative: Topical Fluorides: Evidence-based Guidance on the Use of Topical Fluorides for Caries Prevention in Children and Adolescents in Ireland. 2008. http://ohsrc.html/guidelines. html (accessed February 6, 2015).

Macpherson LM, Ball GE, Brewster L, Duane B, Hodges C-L, Wright W, Gnich W, Rodgers J, Turner S, Conway DI: Childsmile: the national child oral health improvement programme in Scotland. Part 1. Establishment and development. Br Dent J 2010;24:209:73-78.

Moher D, Liberati A, Tetzlaff J, Altman DG; The PRISMA Group: Preferred reporting items for systematic reviews and meta-analyses: The PRISMA statement. PLoS Med 2009; 6:e1000097.

Moyer V; US Preventive Services Task Force: Prevention of dental caries in children from birth through age 5 years: US Preventive Services Task Force recommendation statement. Pediatrics 2014;133:1-10

NHS Business Services Agency Information Services: Fluoride Varnish Challenge, Update April 2013. London, NHS Business Services Agency Information Services, 2015.

New Zealand Guidelines Group: Guidelines for the Use of Fluorides. Wellington, New Zealand Ministry of Health, 2009. http://www. health.govt.nz/system/files/documents/publications/guidelines-for-the-use-of-fluoridenov09.pdf (accessed February 6, 2015).

Primary Care Commissioning: Dental Assurance Framework Policy and Corporate Procedures. March 2014. http://www.england.nhs. uk/wp-content/uploads/2014/04/dental-assurance-frmwrk.pdf (accessed February 6, 2015)

Public Health England: Delivering Better Oral Health - An Evidence-Based Toolkit for Prevention. 2014. https://www.gov.uk/government/uploads/system/uploads/attachment data/file/367563/DBOHv32014OCTMainDocument_3.pdf (accessed February 6, 2015).
Royal Australian College of General Practitioners: Guidelines for Preventive Activities in General Practice, ed 8. Melbourne, RACGP, 2012. http://www.racgp.org.au/download/ Documents/Guidelines/Redbook8/redbook8.pdf (accessed February 6, 2015).

Scottish Dental Epidemiology Co-Ordinating Committee: National Dental Inspection Programme (NDIP) 2014. Report of the $2014 \mathrm{De}-$ tailed National Dental Inspection Programme of Primary 1 Children and the Basic Inspection of Primary 1 and Primary 7 Children. Edinburgh, ISD, 2014. http://www.isdscotland. org/Health-Topics/Dental-Care/ Publications/2014-10-28/2014-10-28-NDIPReport.pdf (accessed February 6, 2015).

Scottish Executive: An Action Plan for Improving Oral Health and the Modernisation of NHS Dental Services in Scotland. Edinburgh, Scottish Executive, 2005.

Scottish Intercollegiate Guidelines Network (SIGN): Dental Interventions to Prevent Caries in Children (SIGN Publication No 138). 2014. http://www.sign.ac.uk (accessed February 6,2015$)$.

Scottish Intercollegiate Guidelines Network (SIGN): Prevention and Management of Dental Decay in the Pre-School Child (SIGN Publication No 83). 2005. http://www.sign. ac.uk (accessed February 6, 2015).

Scottish Intercollegiate Guidelines Network (SIGN): Preventing Dental Caries in Children at High Caries Risk (SIGN Publication No 47). 2000. http://www.sign.ac.uk (accessed February 6, 2015).

Weyant RI, Tracy SL, Anselmo T, Beltrán-Aguilar ED, Donly KJ, Frese WA, Hujoel PP, Iafolla T, Kohn W, Kumar J, Levy SM, Tinanoff N, Wright JT, Zero D, Aravamudhan $\mathrm{K}$, Frantsve-Hawley J, Meyer DM: Topical fluoride for caries prevention. J Am Dent Assoc 2013;144:1279-1291. 